\title{
APT Blanket Thermal Analysis of Cavity Flood Cooling with a Beam Window Break
}

by

M. A. Shadday

Westinghouse Savannah River Company

Savannah River Site

Aiken, South Carolina 29808

L. L. Hamm

This paper was prepared in connection with work done under the above contract number with the U.S. Department of Energy. By acceptance of this paper, the publisher and/or recipient acknowledges the U.S. Government's right to retain a nonexclusive, royalty-free license in and to any copyright covering this paper, along with the right to reproduce and to authorize others to reproduce all or part of the copyrighted paper. 


\section{DISCLAIMER}

This report was prepared as an account of work sponsored by an agency of the United States Government. Neither the United States Government nor any agency thereof, nor any of their employees, makes any warranty, express or implied, or assumes any legal liability or responsibility for the accuracy, completeness, or usefulness of any information, apparatus, product or process disclosed, or represents that its use would not infringe privately owned rights. Reference herein to any specific commercial product, process or service by trade name, trademark, manufacturer, or otherwise does not necessarily constitute or imply its endorsement, recommendation, or favoring by the United States Government or any agency thereof. The views and opinions of authors expressed herein do not necessarily state or reflect those of the United States Government or any agency thereof.

This report has been reproduced directly from the best available copy.

Available for sale to the public, in paper, from: U.S. Department of Commerce, National Technical Information Service, 5285 Port Royal Road, Springfield, VA 22161

phone: (800) 553-6847

fax: (703) 605-6900

email: orders@ntis.fedworld.gov

online ordering: http://www.ntis.gov/ordering.htm

Available electronically at http://www.doe.gov/bridge

Available for a processing fee to U.S. Department of Energy and its contractors, in paper, from: U.S. Department of Energy, Office of Scientific and Technical Information, P.O. Box 62, Oak Ridge, TN 37831-0062

phone: (865)576-8401

fax: (865)576-5728

email: reports@adonis.osti.gov 


\section{DISCLAIMER}

Portions of this document may be illegible in electronic image products. Images are produced from the best available original document. 


\section{APT BLANKET THERMAL ANALYSIS OF CAVITY FLOOD COOLING WITH A BEAM WINDOW BREAK}

M. Andy Shadday

L. Larry Hamm

Westinghouse Savannah River Company

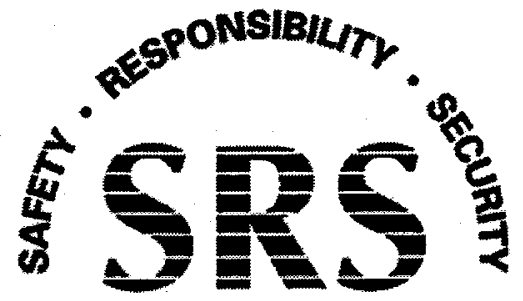


WSRC-TR-99-00347

KEYWORDS:

Accelerator Production of Tritium Blanket System

Conceptual Design

Detailed Bin Model

Safety Analysis

RETENTION - Permanent

\section{APT BLANKET THERMAL ANALYSIS OF CAVITY FLOOD COOLING WITH A BEAM WINDOW BREAK}

SAVANNAH RIVER TECHNOLOGY CENTER

M. Andy Shadday

L. Larry Hamm

Publication Date: September 1999

Westinghouse Savannah River Company

Savannah River Site

Aiken, SC 29808

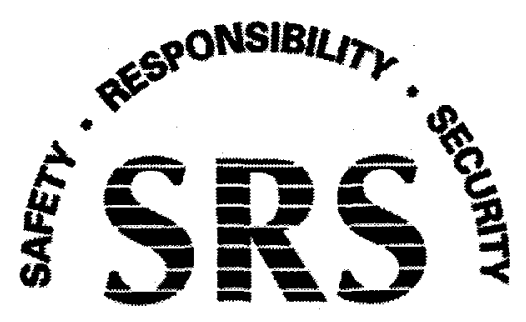

SAVANNAH RIVER SITE

Prepared for the U.S. Department of Energy under Contract No. DE-AC09-96SR18500 
DOCUMENT: WSRC-TR-99-00347

TITLE: APT BLANKET THERMAL ANALYSES OF TOP HORIZONTAL ROW 1 MODULES

APPROVALS
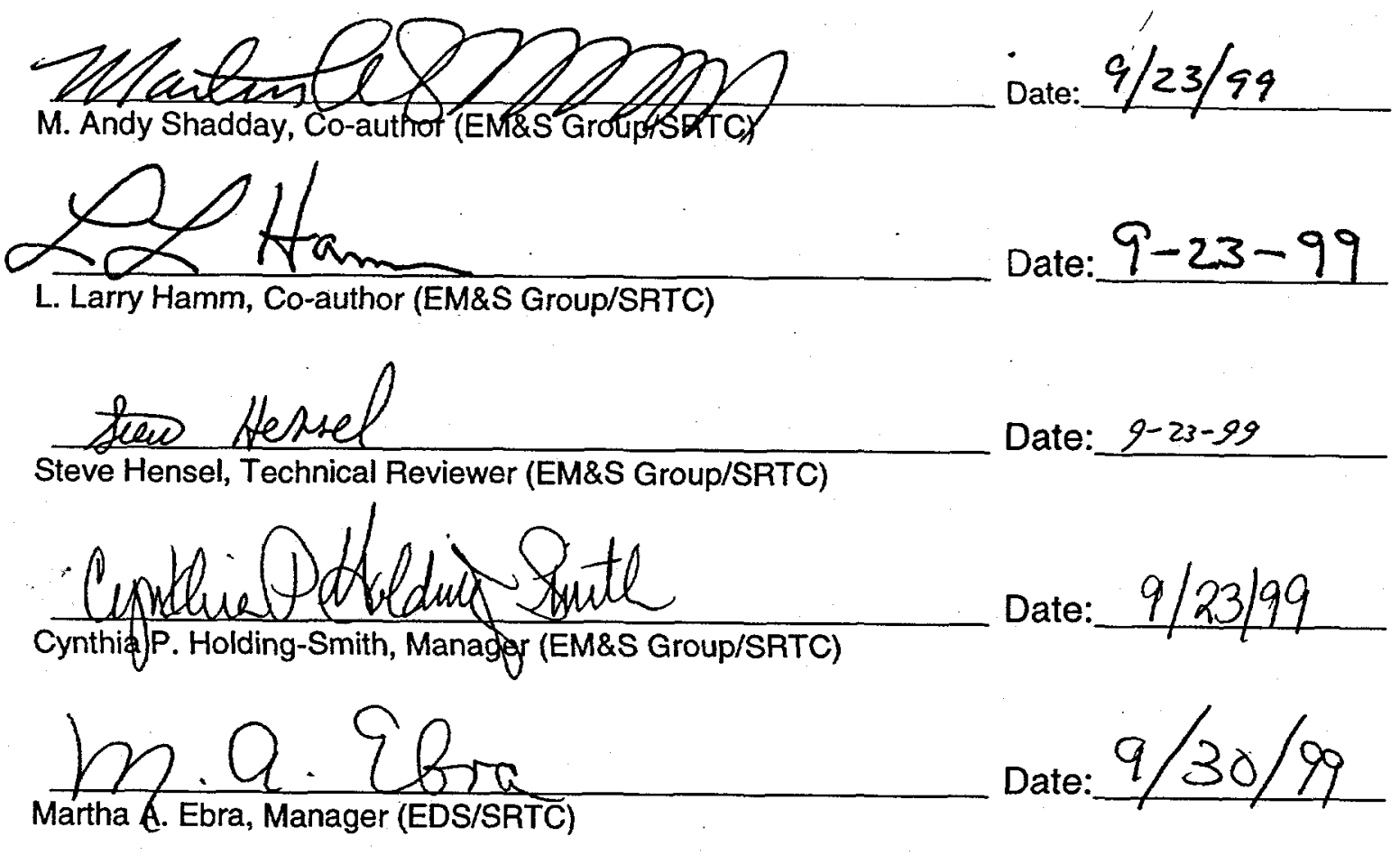

-ii- 


\section{Table of Contents}

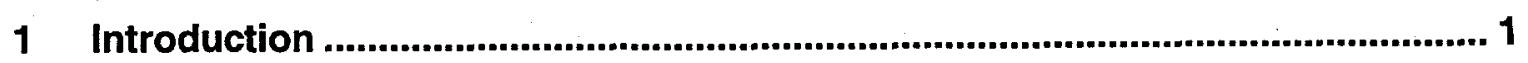

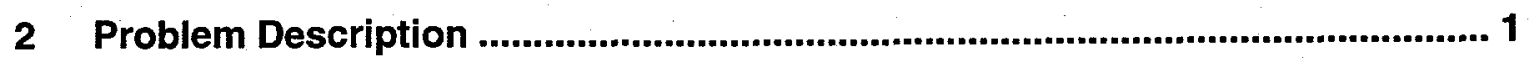

3 Description of the Thermal Conduction Model ............................................... 3

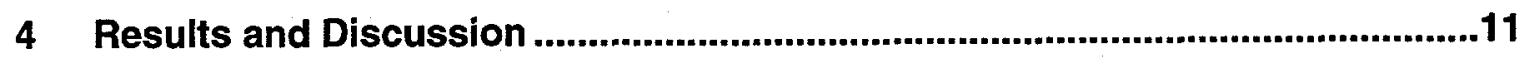

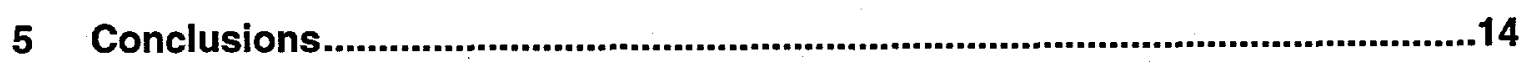

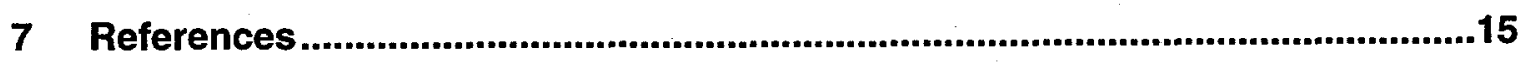




\section{List of Figures}

Figure 1 Schematic of the target vessel showing components to be cooled by the cavity flood system. 2

Figure 2 Transient cavity flood level with a bear window break. ...........................

Figure 3

Axial power density distribution in the downstream row 1 module.

Figure 4 Horizontal lengthwise relative deposited power profiles for plates in the three row 1 modules considered (Solid symbols data, [5], open symbols extrapolated)

Figure 5 Cross-section of a top horizontal row 1 module showing model domain.

Figure 6 The HEATEL finite-element grid (vertical slice) of a top horizontal row 1 module. 9

Figure 7

Figure 8

Decay power curve .10

Axial relative power distribution for the front top horizontal row 1 module. .10

Figure 9

Vertical relative power distribution for the top horizontal modules

Figure 10 Peak metal temperatures in the internally dry downstream row 1 module with delayed cavity flood cooling.

Figure 11. Peak metal temperatures in the internally dry front lateral row 1 module with delayed cavity flood cooling.

Figure 12 Peak metal temperatures in the internally dry back lateral row 1 module with delayed cavity flood cooling.

Figure 13 Peak metal temperatures in the top front row 1 module with delayed cavity flood cooling. 


\section{Introduction}

The cavity flood system is designed to be the primary safeguard for the integrity of the blanket modules and target assemblies during loss of coolant accidents, LOCA's. In the unlikely event that the internal flow passages in a blanket module or a target assembly dryout, decay heat in the metal structures will be dissipated to the cavity flood system through the module or assembly walls. References [1] and [2] document studies that demonstrated that the cavity flood system could adequately cool the lateral, downstream and top row 1 modules. This study supplements the two previous studies by demonstrating that the cavity flood system can adequately cool the blanket modules when the cavity vessel beam window breaks. If the cavity vessel beam window breaks prior to or during the cavity flood process, the time required for the lateral and top blanket modules to be covered by the fluid will be delayed by the diversion of cavity flood fluid into the beam passage. In view of this delay, transient thermal conduction models of row 1 plates in the front and back lateral modules, the down stream module, and the front top module were developed to demonstrate that the cavity flood system can adequately cool the blanket modules.

\section{Problem Description}

The cavity flood system protects the integrity of the target and blanket in the event of an accident that leaves either system partially or wholly internally dry. The cavity vessel is flooded with water that cools the outer surfaces of the blanket modules. Simultaneous with an accident that drains a blanket module, the beam window is assumed to break. The entire aperture is assumed to be available for flow out of the cavity vessel. Filling the last section of the beam passage where the beam is rastered delays the covering of the blanket modules. Figure 1 is a schematic of the cavity vessel that shows the target ladders and the blanket modules. The cavity flood system is assumed to have a steady-state free surface elevation of $-0.8 \mathrm{~m}$. The tops of the lateral and top blanket modules are at approximately $-9.0 \mathrm{~m}$. The target ladders span the elevation range from 11.9 to $-10.0 \mathrm{~m}$, and the beam window is at the same elevation as the target ladders. Figure 2 shows the cavity flood level as a function of elapsed time from beam shutdown, [3]. System activation is delayed for 70.0 seconds. The elevation at which cavity flood coolant starts pouring through the beam window break is approximately $-11.9 \mathrm{~m}$. This is evident from the drop in the cavity vessel fill rate in Fig. 2 . The blanket modules are covered at approximately 250.0 seconds. The beam window break delays immersion of the blanket modules by approximately 100.0 seconds. The question addressed by this study is whether these delays are sufficient to allow portions of internally dry modules to overheat. 


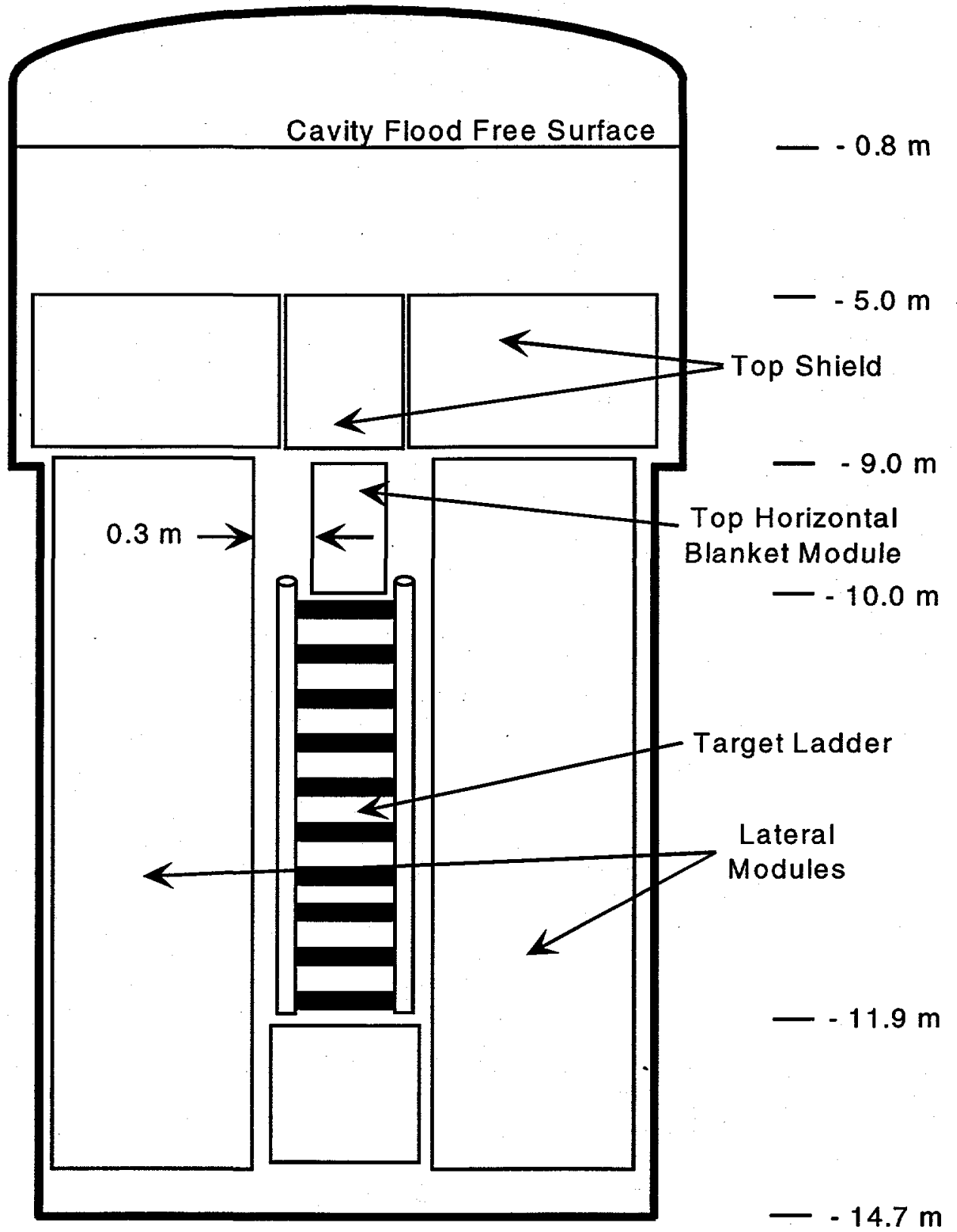

Figure 1 Schematic of the target vessel showing components to be cooled by the cavity flood system. 


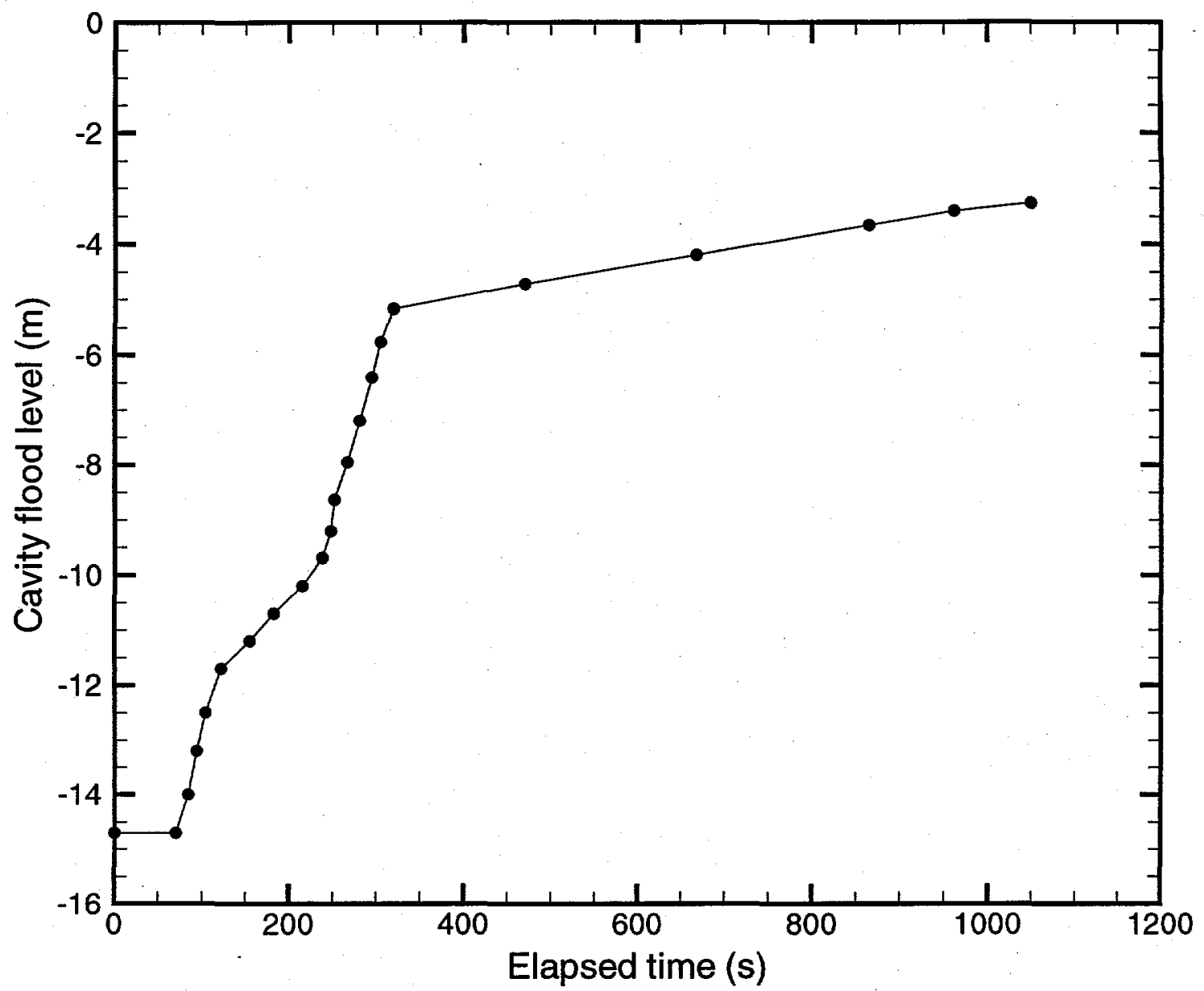

Figure 2 Transient cavity flood level with a beam window break.

\section{Description of the Thermal Conduction Model}

Two distinct models were used in this study: one for the lateral and downstream modules, and the other for the top module. A single plate in the front or back lateral or the downstream row 1 module was modelled with HEATEL, a transient three-dimensional thermal conduction code. In all three cases the plates considered are the nominal 7.5" design, [1]. The highest power or "hot" plate and an average power plate in each module is considered. To address the top module, a three-dimensional transient thermal conduction model of the front row 1 module, using HEATEL, was developed, [2].

Considering a single plate for the lateral and downstream modules substantially reduces the size and complexity of the numerical model, and since thermal conduction with adjacent plates is neglected, this will be bounding for the hot plate in a module. When a module is internally dry, the heat transfer between adjacent plates will essentially be confined to thermal conduction through the thin 
aluminum flow-channel walls; and although there can be a large difference in deposited power between ends of a module, the deposited power difference between adjacent plates is small. In view of the good path for thermal conduction in the lateral direction towards the cooled module wall, heat transfer between adjacent plates is negligible. For the sake of expediency, the plate design used in the original draft of the PSAR [4] was stretched to the dimensions of the 7.5" design. The decay power in a module varies both temporally and spatially. It drops off very steeply after beam shutdown to approximately one percent after ten seconds. Thereafter the decay is much slower. The power decay is included in the model. The vertical relative power density distribution for the downstream module is shown in Fig. 3 . The power density distributions for the other two modules are similar. Figure 4 shows the horizontal lengthwise power density distributions for plates in the three modules. Both vertical and horizontal power density distributions are incorporated in the plate models. The power density distribution in the horizontal direction normal to the stacked plates is accounted for by modelling either the hot plate or the mean power plate in a module. Table 1 shows the mean and hot plate powers for the lateral and downstream modules.

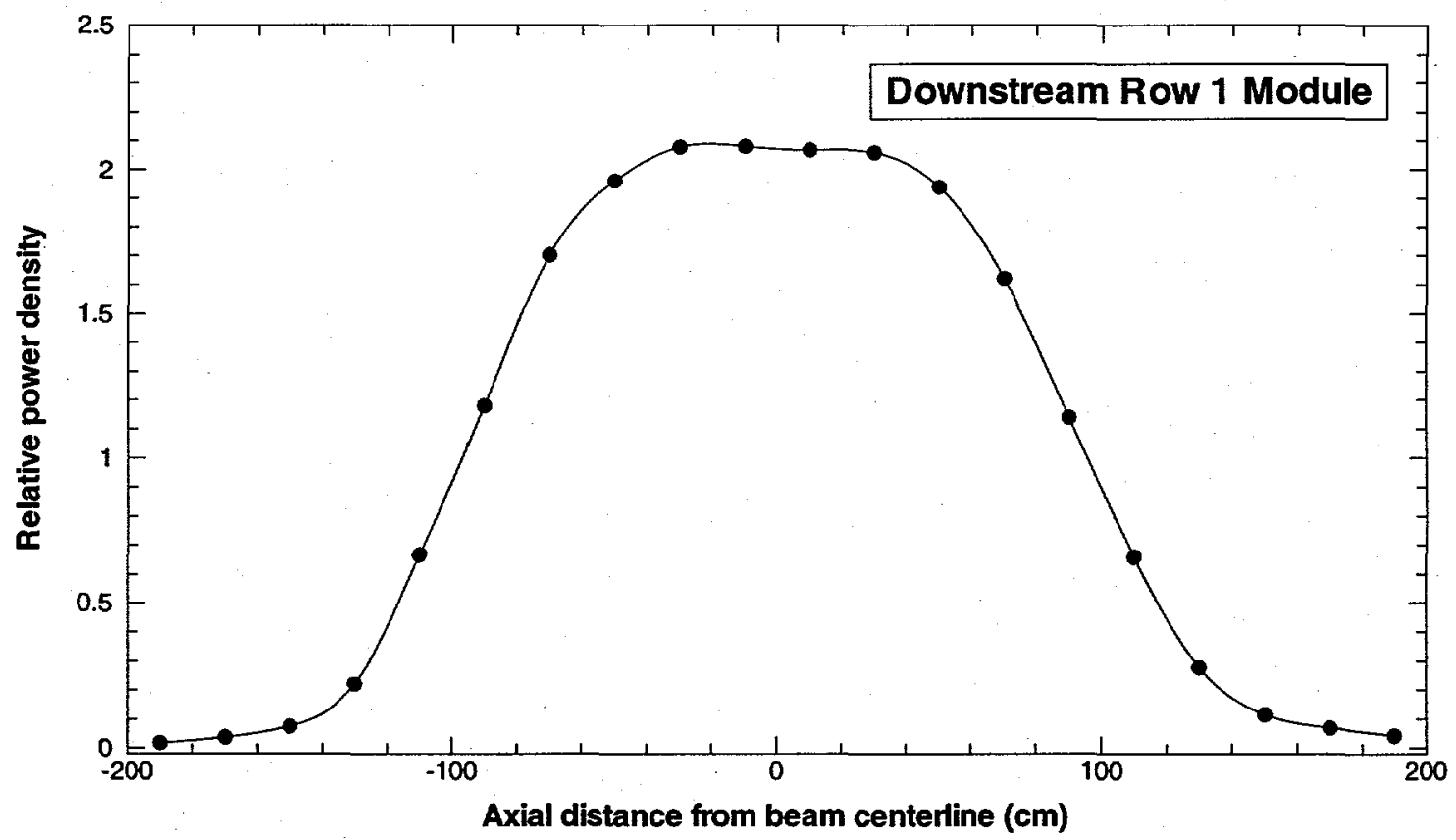

Figure 3 Axial power density distribution in the downstream row 1 module. 


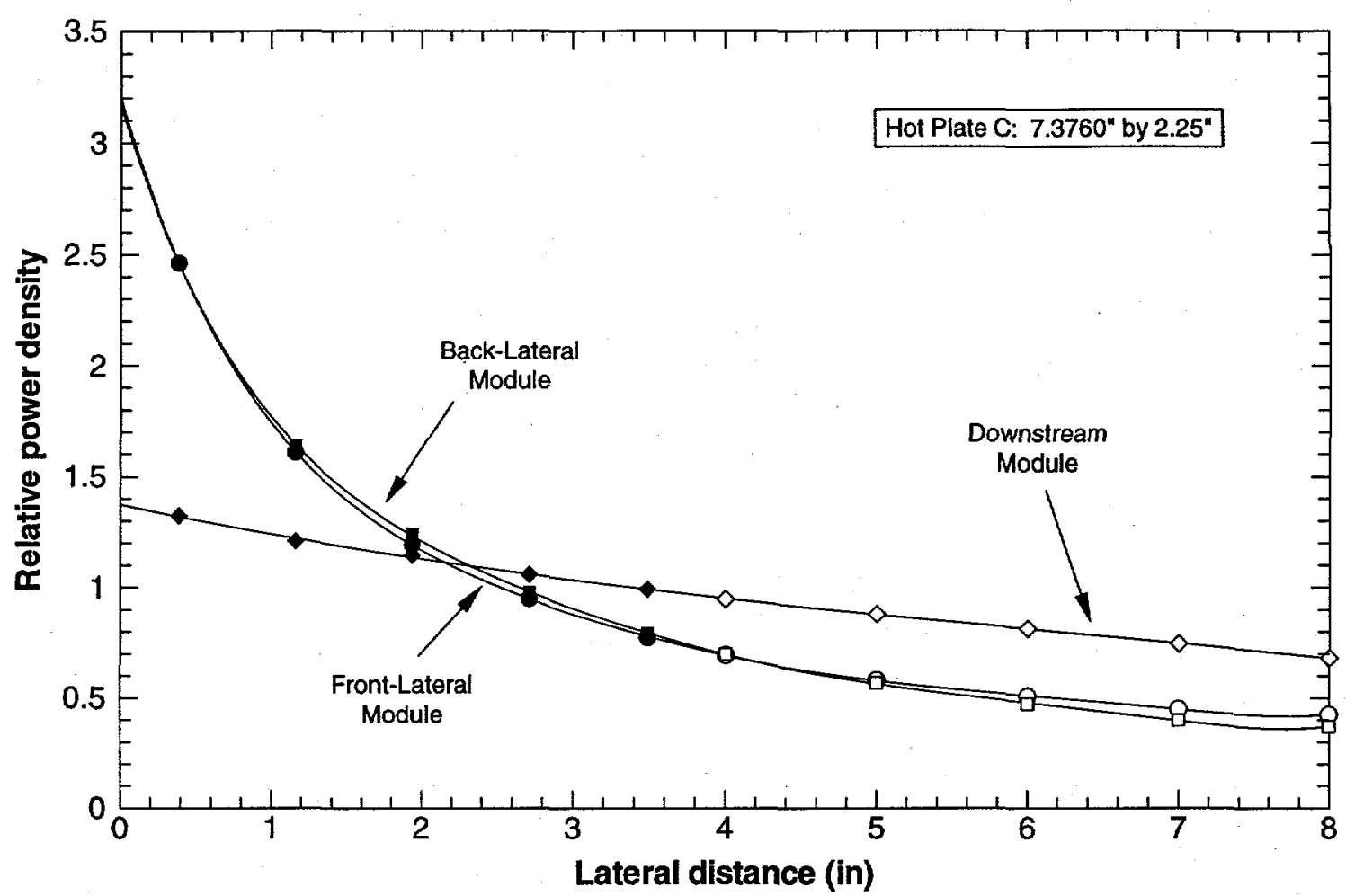

Figure 4 Horizontal lengthwise relative deposited power profiles for plates in the three row 1 modules considered (Solid symbols data, [5], open symbols extrapolated).

Table 1 Pre-incident powers for the three modules

\begin{tabular}{|c|c|c|}
\hline Module & Mean Plate Power & Hot Plate Power \\
\hline Front Lateral Module & $65.7 \mathrm{~kW}$ & $104.5 \mathrm{~kW}$ \\
\hline Back Lateral module & $94.4 \mathrm{~kW}$ & $130.1 \mathrm{~kW}$ \\
\hline Downstream Module & $139.4 \mathrm{~kW}$ & $189.6 \mathrm{~kW}$ \\
\hline
\end{tabular}

The modelled module is assumed to dryout at 5.0 seconds after beam shutdown, and at this time the plate temperature is assumed to be uniform at $100.0^{\circ} \mathrm{C}$. The plate is assumed to heat adiabatically until the cavity flood level reaches the top of the module, 238 seconds after beam shutdown. Thereafter the low power end of the plate, the one opposite the decoupler end, is cooled by the cavity flood fluid. The plate is cooled by single-phase convection with a heat transfer coefficient for laminar flow through a one inch gap of $72.4 \mathrm{~W} / \mathrm{m}^{2} \mathrm{~K}$, or if the wall superheat exceeds $15^{\circ} \mathrm{C}$, by a boiling heat transfer coefficient of $2000 \mathrm{~W} / \mathrm{m}^{2} \mathrm{~K}$. The free stream temperature is assumed to be the local saturation temperature. This temperature increases with time until the cavity flood level reaches the steady-state level of $-0.8 \mathrm{~m}$ at 1866.0 seconds. 
The top module geometry precludes the modelling of a single plate. There are two sets of horizontal top blanket modules, front and back sets, that are positioned above the target ladders and are oriented parallel to the accelerator beam. Figure 5 is a schematic of one of the row 1 top modules. It shows a vertical cross-section in a plane normal to the accelerator beam. The interior flow channels extend horizontally the entire axial length of the module. There are four parallel lead plates that extend the entire length of the module in the beamwise direction. The plates are separated by the helium tubes and flow channels, and they are clad with aluminum. There is a decoupler below the module and a row 2 module above. The two sides of the module are exposed to the cavity flood fluid when this system is activated, and decay heat is transferred to the cavity flood fluid through these surfaces when there is no flow through the internal flow channels.

The parallel planes of the plates are oriented vertically, which is not the orientation most conducive for effective thermal conduction to the vertical sides of the module. When the flow channels are completely voided, conduction between the inner and outer plates can effectively occur only through the aluminum walls of the flow channels that enclose the helium tubes and the top and bottom module walls.

A three-dimensional transient thermal conduction model of the front top row 1 module, using HEATEL, was developed. The boundary conditions and decay power distributions are symmetrical with respect to a vertical plane that bisects the central flow channels and helium tubes, so only half of the module was modelled. The top, bottom, and symmetry plane boundaries are adiabatic, and the vertical sidewall is subjected to convection cooling by water at the local saturation temperature. Two values of the convection heat transfer coefficient were used: 72.4 and $537.0 \mathrm{~W} / \mathrm{m}^{2} \mathrm{~K}$. The first value is the heat transfer coefficient used for the lateral and downstream modules, and it is used in this model for comparison. The second value is the natural convection heat transfer coefficient for a vertical plate with a specified heat flux of $3.88 \mathrm{~kW} / \mathrm{m}^{2}$, [2].

Instead of modelling the complicated plate geometries of the module, a simplified Cartesian grid, shown in Fig. 6 was used. The rectangular inclusions represent the flow channels, the four in the exterior aluminum wall and the row of flow channels separating the interior and the peripheral lead plates. The right side of the grid is a plane of symmetry and therefore adiabatic. Because this surface is adiabatic, neglecting the additional surface area due to the semi-circular helium tube indentations is reasonable. The cross-sectional areas of the two lead plates are preserved. All of the heat transfer between the two plates is assumed to occur by thermal conduction through the narrow aluminum "bridges" that separate the flow channels. The lengths and widths of these "bridges" are preserved. Since the surfaces of the flow channels are assumed to be adiabatic, the flow channel geometries are not important. The top and bottom grid 
boundaries are adiabatic surfaces. The decoupler is below the module, and the row 2 module is above. The left side of the grid is the left vertical exterior surface of the module that is exposed to the cavity flood fluid. The cavity flood fluid, which is assumed to be at the local saturation temperature, convectively cools this surface. There is assumed to be a one mil. air-filled gap between the lead and the aluminum. The temperature distribution shown in Fig. 6 is the distribution at the high power end of the module at the time that the highest peak temperature occurs.

In the HEATEL model, all of the decay power is assumed to be generated in the lead, and it varies both spatially and temporally. The power source terms are based on physics calculations for $1700 \mathrm{MeV}$ protons with a beam current of 100 $\mathrm{mA},[5]$. The spatial power distribution varies in the beamwise direction and in the vertical direction. The decay curve is a function of elapsed time from beam shutdown. The steady-state operating power for half of the front row 1 module is $144.5 \mathrm{~kW}$. This power drops precipitously when beam shutdown occurs. Within ten seconds the power will have dropped below one percent of the steady-state value. The decay curve is shown in Fig. 7. Figure 8 shows the axial power density distribution for the front top horizontal row 1 module. The axial distance is measured from the rear of the module, where the peak power density occurs. The module power density is a minimum at the front of the module. Figure 9 shows the vertical steady-state axial averaged power density variation for the lead in the top modules. The vertical dimension is measured from the bottom of the row 1 module, and the row 1 module spans the distance from 0.0 to 19.04 $\mathrm{cm}$. Note that the vertical ordinate of the plot is the natural logarithm of the power density. In HEATEL this curve is normalized to the mean power density, so it determines the vertical spatial distribution of the relative power density. 


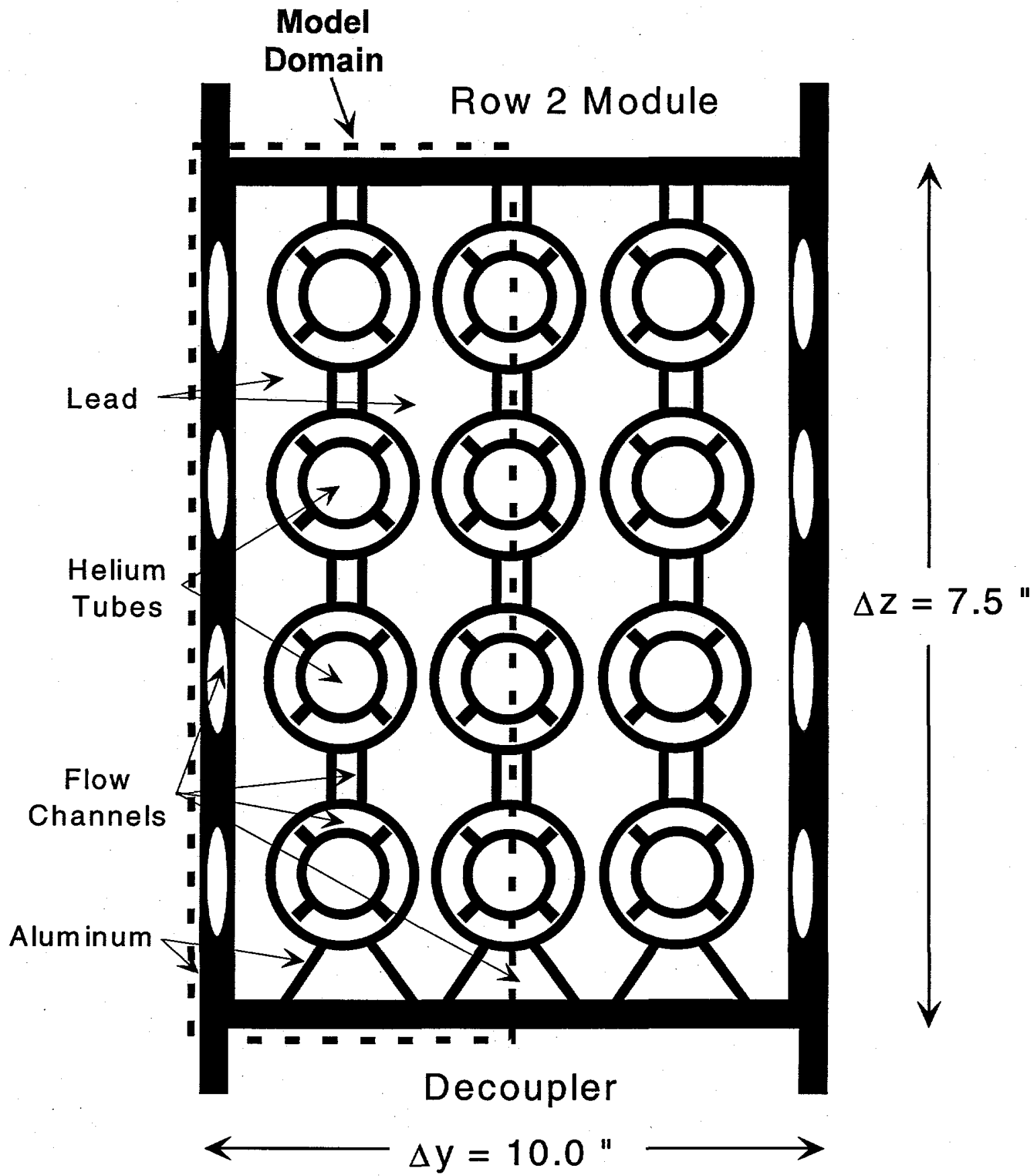

Figure 5 Cross-section of a top horizontal row 1 module showing model domain. 


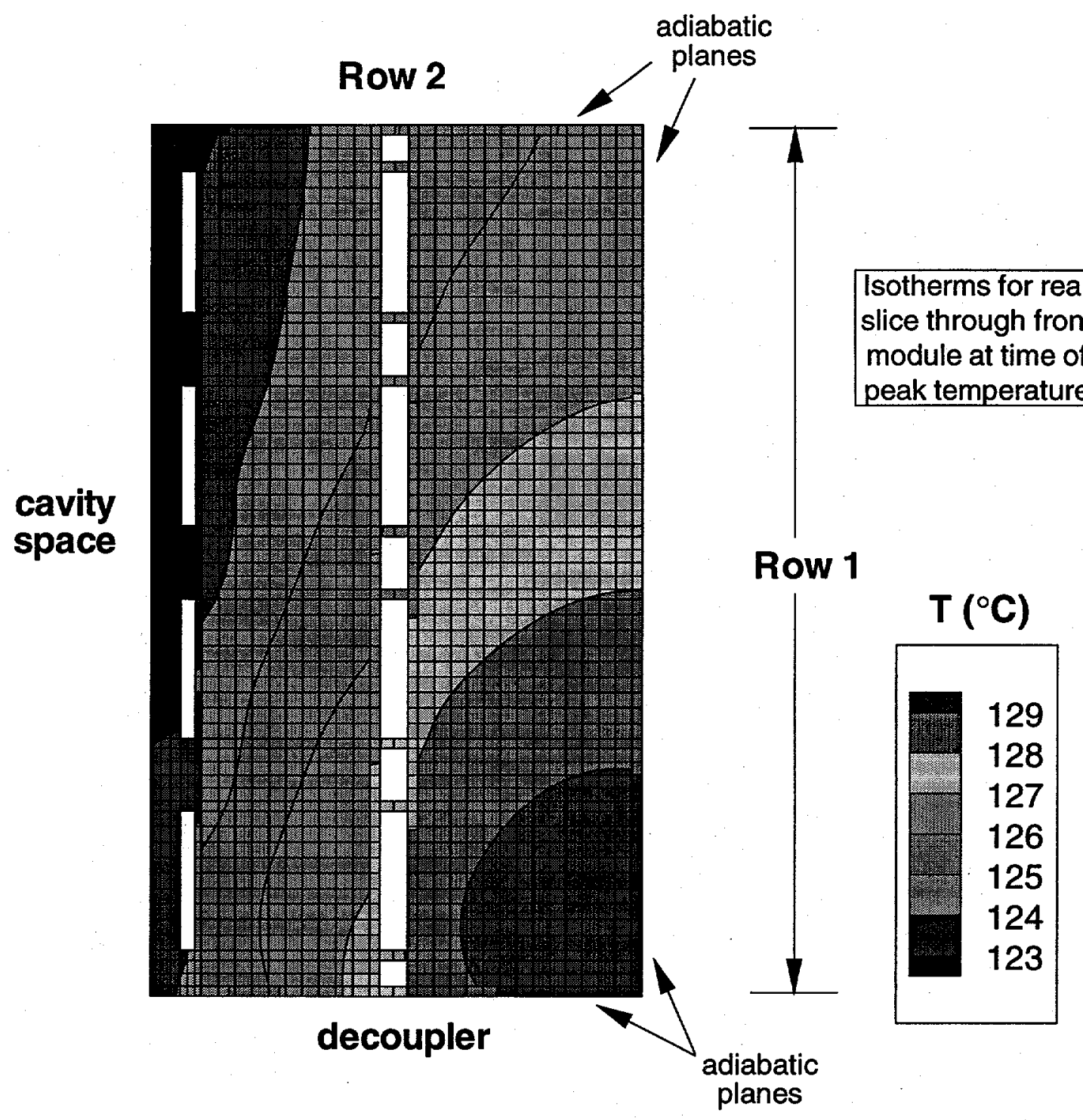

Figure 6 The HEATEL finite-element grid (vertical slice) of a top horizontal row 1 module. 


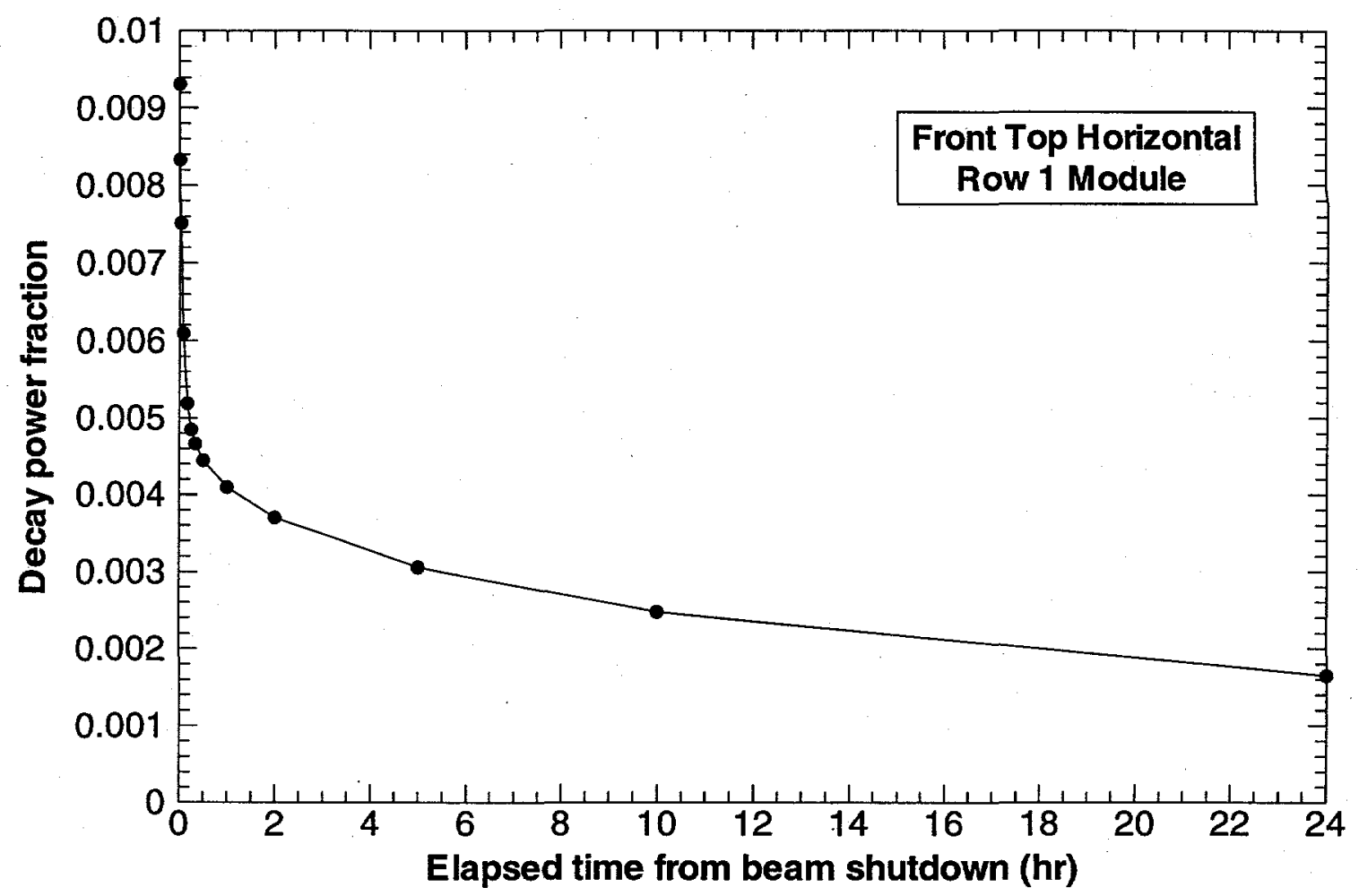

Figure 7 Decay power curve.

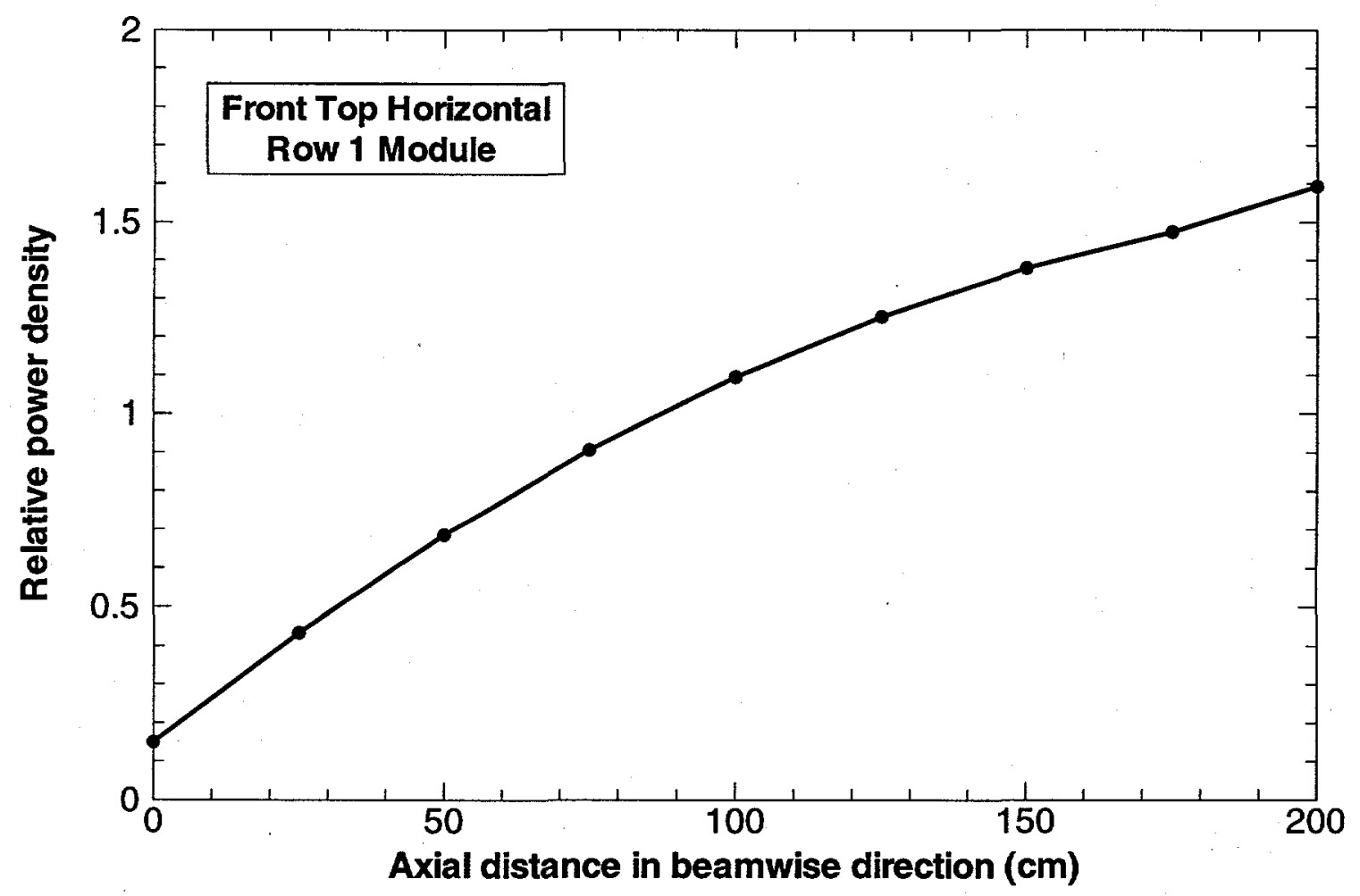

Figure 8 Axial relative power distribution for the front top horizontal row 1 module. 


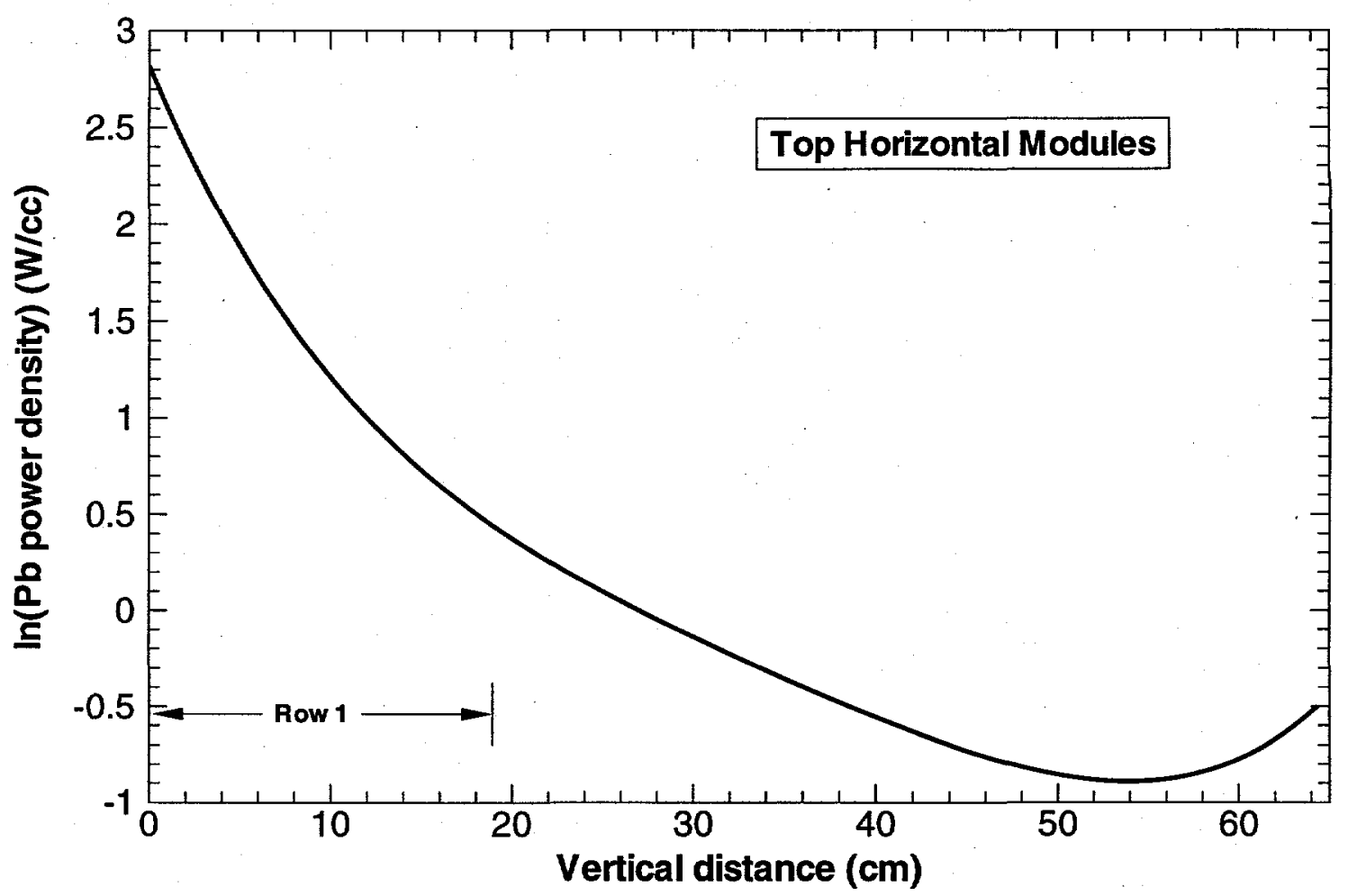

Figure 9 Vertical relative power distribution for the top horizontal modules.

\section{$4 \quad$ Results and Discussion}

Figures 10 through 12 show the transient peak metal temperatures for the hot plate and the mean power plate in the downstream and front and back lateral modules respectively. The downstream module has the highest mean power density and also the highest power plate in the blanket. The highest peak metal temperature in the hot plate is $158.6^{\circ} \mathrm{C}$, and in the mean power plate it is $151.7^{\circ} \mathrm{C}$. The peak metal temperature in the hot plate remains above the $150^{\circ} \mathrm{C}$ long term temperature limit for approximately 8.3 hours, and for approximately 1.6 hours in the mean power plate. The highest peak metal temperature of the hot plate in the front lateral row 1 module is $150.5^{\circ} \mathrm{C}$, and the peak temperatures in the mean power plate remain below the $150^{\circ} \mathrm{C}$ temperature limit. The highest peak metal temperature of the hot plate in the back lateral row 1 module is $154.0^{\circ} \mathrm{C}$, and $149.3^{\circ} \mathrm{C}$ for the mean power plate.

Figure 13 shows the transient peak metal temperatures for the front top row 1 module. Results are shown for two values of the heat transfer coefficient: 72.4 $\mathrm{W} / \mathrm{m}^{2} \mathrm{~K}$, the value used with the lateral and downstream modules, and 537.0 $\mathrm{W} / \mathrm{m}^{2} \mathrm{~K}$, the value for natural convection from a vertical surface. The latter value is the more appropriate for the top module geometry, though the peak metal temperatures are not very sensitive to the value of the heat transfer coefficient. 
The highest peak metal temperature with a heat transfer coefficient of 537.0 $\mathrm{W} / \mathrm{m}^{2} \mathrm{~K}$ is $129.6^{\circ} \mathrm{C}$.

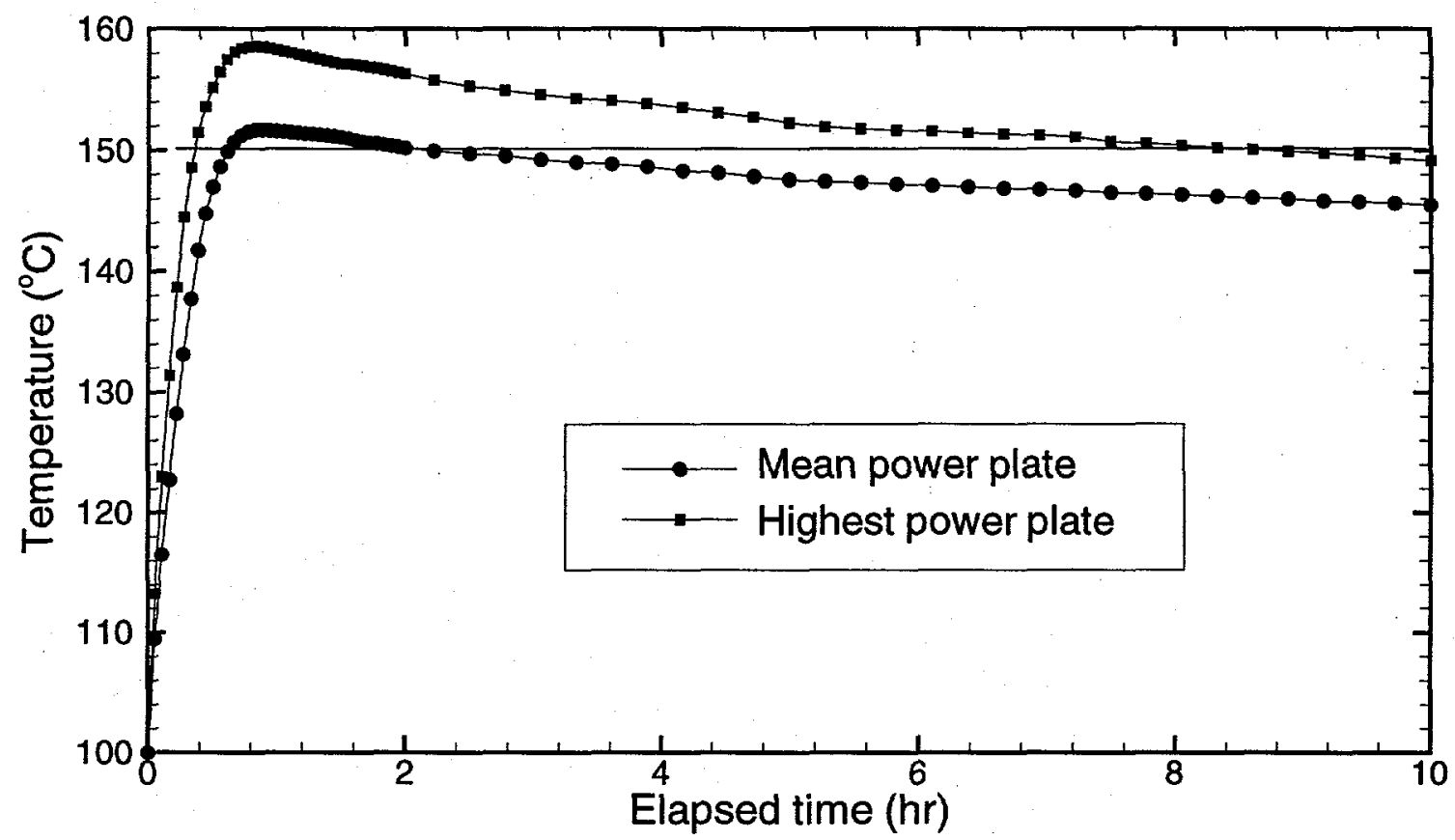

Figure 10 Peak metal temperatures in the internally dry downstream row 1 module with delayed cavity flood cooling.

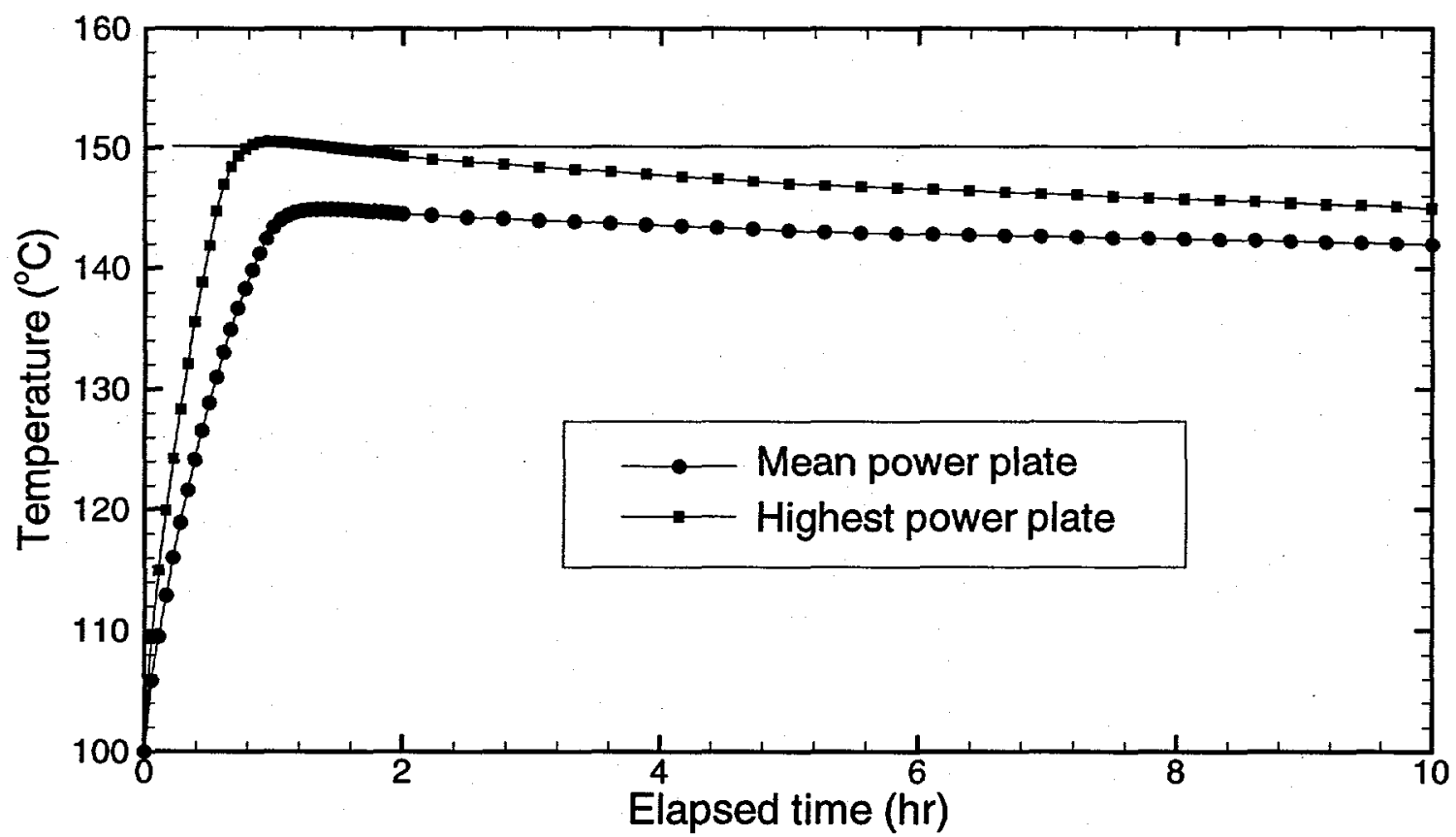

Figure 11 Peak metal temperatures in the internally dry front lateral row 1 module with delayed cavity flood cooling. 


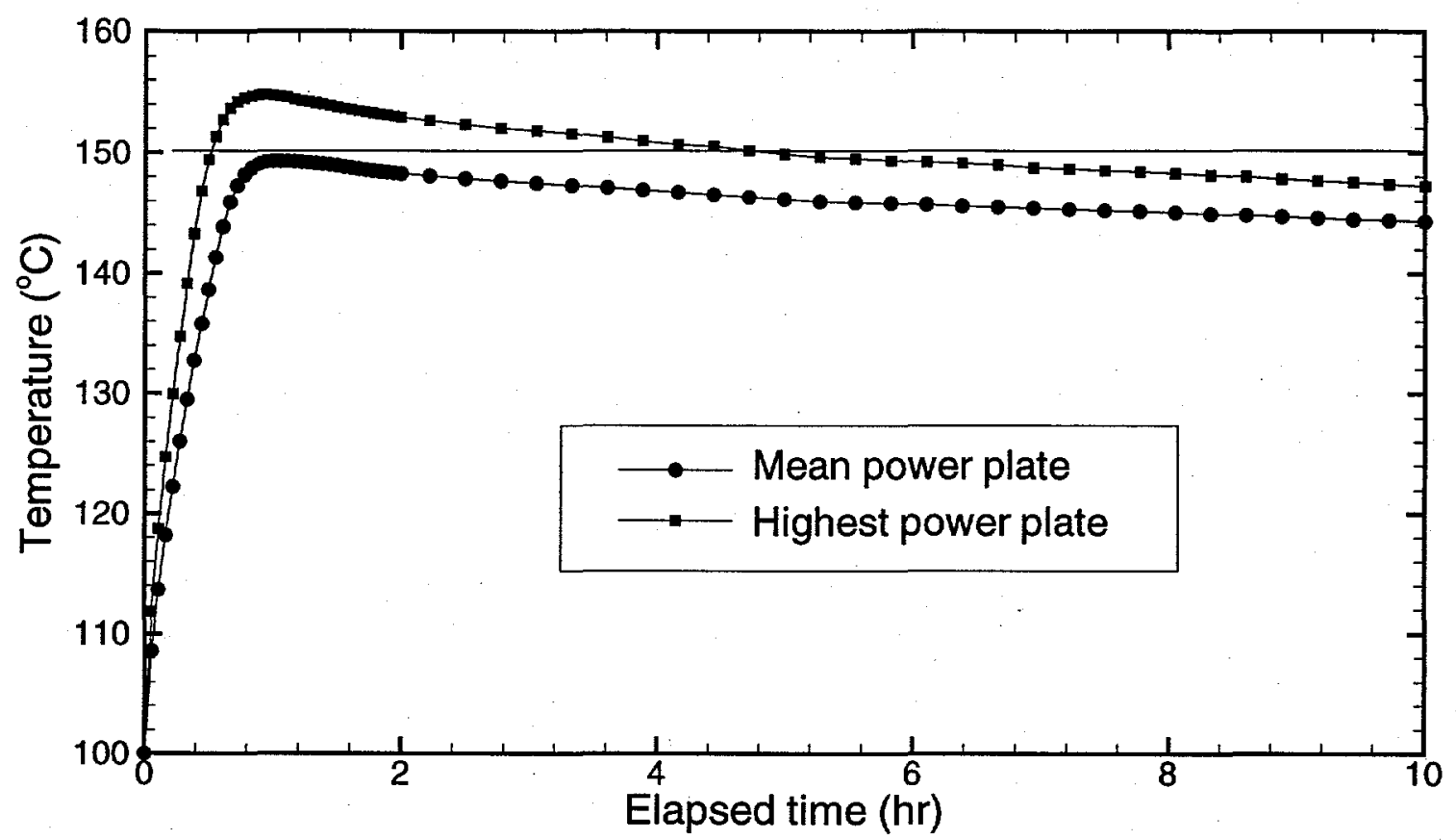

Figure 12 Peak metal temperatures in the internally dry back lateral row 1 module with delayed cavity flood cooling.

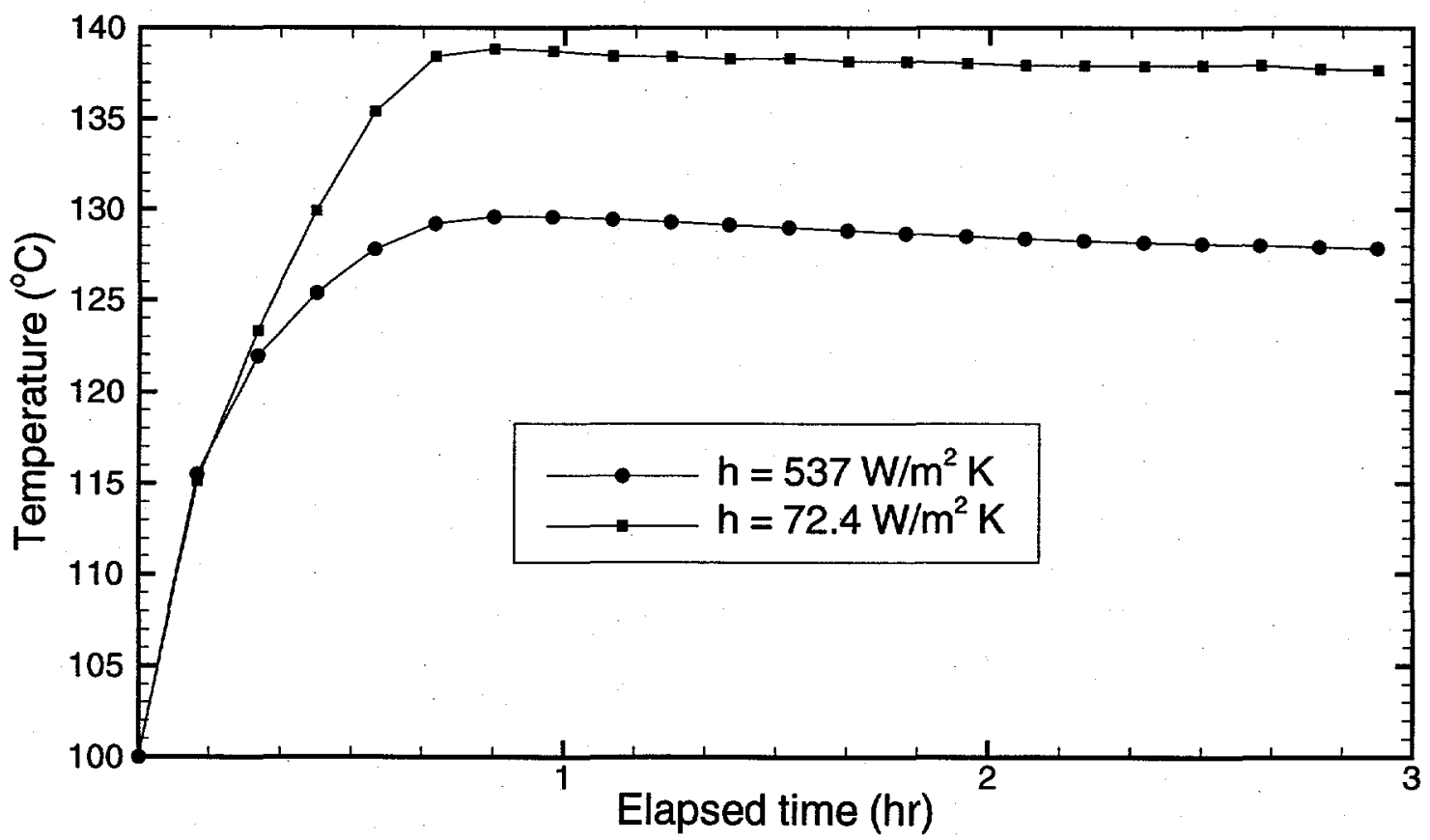

Figure 13 Peak metal temperatures in the top front row 1 module with delayed cavity flood cooling. 
The peak metal temperatures in the downstream and back lateral row 1 modules exceed the $150^{\circ} \mathrm{C}$ long-term exposure metal temperature limit for blanket components for a brief period, 8.3 hours for the hot plate in the downstream module and 4.5 hours for the hot plate in the back lateral row 1 module. The hot plate in the front lateral row 1 module reaches but does not exceed this temperature limit. The peak temperature in the front top row 1 module remains well below this temperature limit. Since the decay powers in the row 1 modules bound that in the modules further removed from the target, the two blanket modules in which the metal temperature can exceed $150^{\circ} \mathrm{C}$ have been identified. Since this temperature limit applies to exposures in excess of 10,000 hours. The exposure time limit is not approached.

The most conservative aspect of this study is the five-second dryout assumption. There is no realistic accident scenario that will completely drain a module in five seconds, and therefore this assumption is certainly bounding. The assumed initial temperature of $100^{\circ} \mathrm{C}$ is also very conservative. The peak steady-state operating temperature for a row 1 module is less than $60^{\circ} \mathrm{C}$, and the decay power drops precipitously at beam shutdown. The power is not available to heat the metal in a module by $40^{\circ} \mathrm{C}$ in several seconds. The initial slope of the hot plate peak temperature for the downstream module, Fig. 10 , is $0.048^{\circ} \mathrm{C} / \mathrm{s}$, and this is almost three orders of magnitude lower than that required for the $100^{\circ} \mathrm{C}$ initial condition. The assumption that no heat dissipation to the cavity flood system occurs until the tops of the modules are covered is another conservative assumption. While this is realistic for the top module, the high power regions in the lateral and downstream modules are in the vicinity of the vertical midpoints. While the modules are partially immersed, the portions of the modules that are under water will be cooled.

\section{Conclusions}

In view of the extremely conservative nature of the modelling assumptions, the conclusion that the cavity flood delay due to a beam window rupture will not adversely affect the cooling capability of the cavity flood system is certainly warranted. The $150^{\circ} \mathrm{C}$ temperature limit is exceeded by most of the plates in the downstream module and less than half the plates in the back lateral row 1 module. These are the only plates in the blanket in which this temperature limit is exceeded, and then only for a relatively short period of time. The maximum time duration for temperatures in excess of $150^{\circ} \mathrm{C}$ is much less than the exposure limit applicable to this temperature limit. 


\section{References}

1. M. A. Shadday, and L. L. Hamm, "A Thermal Conduction Analysis of Proposed Lateral and Downstream Row 1 Module Design Plates," Westinghouse Savannah River Company, WSRC-TR-99-00181 (July 1999).

2. M. A. Shadday, and L. L. Hamm, "APT Blanket Thermal Analyses of Top Horizontal Row 1 Modules," Westinghouse Savannah River Company, WSRC-TR99-00228 (July 1999).

3. B. Lin, EXCELL Spread Sheet: Cavity Water Level vs Time, received from Los Alamos National Laboratory, August 12, 1999. 